\title{
Discriminative avoidance learning in hippocampal and cortical rats: Acquisition rate, behavioral strategies, and long-term retention
}

\author{
SUSAN J. SARA \\ Division of Behavioral Neurology, New York University Medical School, New York, New York 10010 \\ and Center for Experimental and Comparative Psychology, University of Louvain \\ 3041 Pellenberg, Belgium \\ and \\ MICHÈLE DAVID-REMACLE \\ Center for Experimental and Comparative Psychology, University of Louvain \\ 3041 Pellenberg, Belgium
}

\begin{abstract}
Facilitation of visually discriminated avoidance learning was observed in rats 1 week after they were lesioned in the dorsal hippocampus. While perseveration of a spatial strategy acquired during a pretraining session occurs in sham-operated and cortically lesioned controls, no such perseveration was observed in hippocampals. Elimination of the presurgical shaping session reduced the number of spatial strategies in all groups, but differences in trials to criterion and percentage of place strategies remained. Retesting the animals 3 weeks after training showed that hippocampals and corticals had poorer retention than did shams. There were no differences in retention of groups tested $24 \mathrm{~h}$ after training. The long-term retention deficit seems to be independent of the fact that hippocampals learn faster, since cortically lesioned animals also showed the memory deficit, compared with controls, even though they had as many training trials. The results are taken as a demonstration of lesion-induced anterograde amnesia in the rat.
\end{abstract}

The effect of bilateral lesions in the septohippocampal system on learning and memory has received enormous attention in the past 20 years. The effects of the lesions are task dependent and are rather consistent within tasks. From these studies have emerged several theories of hippocampal function, developed by various investigators in the course of comprehensive reviews of the literature. The most widely held theory holds that the main function of the septohippocampal system is to inhibit behavior in appropriate environmental situations. This theory has been expressed in various forms by different authors (Altman, Brunner, \& Bayer, 1973; Douglas, 1975; Gray, Rawlins, \& Feldon, 1977; Kimble, 1968) and appears to have a firm empirical foundation, in such tasks as passive avoidance, reversal learning, and resistance to extinction. However, careful examination of the data and results of more recent experiments have cast doubt on an exclusively

This research was supported by a grant from "Fonds pour le dévelopment scientifique" of the University of Louvain and by NIMH Grant MH 34164-01. The authors thank M. Bronchart and C. Gadessieux for technical assistance and Prof. M. Meulders for making available his facilities for histology. Reprint requests should be sent to S. J. Sara, whose present address is: LPN, Department of Psychophysiology, CNRS, 91190, Gif-sur-Yvette, France. inhibitory role for the hippocampus (see Black, 1975).

Solomon has shown, for example, that although rabbits with hippocampal lesions do not show latent inhibition or blocking effects as do intact animals, they do respond normally in a Pavlovian conditioned inhibition paradigm. This investigator questions, then, the generalization that the hippocampus is critical to inhibition processes. He suggests, instead, that the hippocampus is intimately involved in learning to ignore irrelevant stimuli or in "tuning out stimuli that have no motivational significance for the organism" (Solomon, 1977, p. 416; see also Solomon, 1979).

A more recent hypothesis concerning the function of this system, also supported by strong empirical evidence, is one implicating the hippocampus in spatial elaboration or "cognitive mapping" (O'Keefe \& Black, 1978; O'Keefe \& Nadel, 1979; Olton \& Samuelson, 1976). This view has been supported by lesion studies which show selective deficits in spatial discrimination (Mahut, 1972; O’Keefe, Nadel, Keighthy, \& Kill, 1975) and by single-unit recording of hippocampal neurons which signal an animal's place in an environment (O'Keefe \& Conway, 1978).

One of the tasks in which hippocampally lesioned (HL) or septally lesioned rats have been found to perform consistently better than intact control rats is the 
two-way shuttle avoidance. O'Keefe and Black (1978) count 20 separate studies of HLs that show facilitation of shuttlebox learning; Grossman (1978) indicates that the literature is just as vast and the results just as homogeneous on this point for septally lesioned rats. These results have been used to support both the spatial hypothesis and the behavioral inhibition hypotheses. Thus, it has been suggested that HL rats learn to shuttle faster because they are not impaired by the initial freezing (behavioral inhibition) that is the response to footshock in the early stages of training in the normal rat (Green, Beatty, \& Schwartzbaum, 1967). On the other hand, those who attribute a spatial elaboration role to the hippocampus suggest that HL rats can learn to shuttle faster than normal rats because they do not associate the shock with a specific place and therefore do not have to overcome the initial fear of shuttling to a place where shock has been received (Black, Nadel, \& O'Keefe, 1977).

To test the hypothesis that HL rats learn a two-way avoidance faster because they lack a maladaptive place strategy, we used a visually discriminated avoidance task, which also required the rat to return to the place where it had experienced both a shock and a locked door, a secondary reinforcement. This task lent itself to an analysis of the strategies that animals use in solving the avoidance problem. Our preliminary studies had shown that HLs learned this task in fewer trials than sham-lesioned ones (SLs). There have been several studies of appetitive brightness or form discrimination in HL rats suggesting that the lesion has no effect on acquisition rate of the simultaneous discrimination when it is food or water rewarded (Kimble \& Kimble, 1970; Winocur \& Olds, 1978). Isaacson and Kimble (1972) analyzed the strategies of the animals during acquisition and found that the lesioned rats showed fewer changes in strategies, that is, that they perseverated to a greater degree than did controls, although this did not seem to interfere with the rate of acquisition. In acquisition, the perseveration occurred only with place strategies, not with visual ones; during extinction, the lesioned animals perseverated on the brightness cue more than did the controls.

One of the aims of this study was to examine, in detail, the acquisition of a discriminated avoidance response in the HL rat to confirm our preliminary observation that this avoidance task, like the shuttlebox, is acquired at a faster rate in HLs. We wanted to analyze the strategies used by the animals during training to see to what extent the HL rat relies on place strategy during the early stages of training in an avoidance situation and to determine to what extent animals perseverate in their maladaptive place strategies. Detailed observation of behavior during acquisition, such as reactivity to shock and localization errors, might also be helpful, we thought, in accounting for differences in acquisition rates. Osborne and Black (1978) have discussed and demonstrated the value of detailed analyses of the behavior in lesioned animals.

A function of the hippocampus that has been less well documented in the animal literature is that of memory elaboration and retrieval; as Weiskrantz (1977; Weiskrantz \& Warrington, 1975) has pointed out, this failure to find reliable memory deficits in hippocampally lesioned rats is one of the paradoxes of comparative neuropsychology, since memory dysfunction is an important feature of the temporal lobe syndrome in humans. It has been suggested by several authors that this discrepancy exists between the animal and the human literature, not because the hippocampus has different functions in different species, but because conditions under which memory is investigated in rats and in humans are quite different (see Gaffan, 1972; Isaacson, 1972; Iverson, 1976; Weiskrantz, 1977). Several recent studies have attempted to use experimental conditions with rats that are analogous to those used with humans and have found memory deficits in HL rats. Jarrard (1975) found memory deficits in HLs if there was interpolated activity between learning and retention testing. Winocur's (Winocur \& Bindra, 1976; Winocur \& Olds, 1978) work suggests that HLs have good memories only when the experimental situation is exactly the same during testing as it was during training, which is more likely in animal experiments than in human clinical situations. Gaffan (1972) has provided some evidence that HLs are deficient in recognition memory.

To our knowledge, there have been no studies of the memory of the HL rat after a long training-to-test interval, that is, no investigations of the long-term retention capacity and information retrieval processes. We have evidence that forgetting in normal rats after a long training-to-test period is due to retrieval failure (Deweer, Sara, \& Hars, 1980; Sara, Deweer, \& Hars, 1976). It has been suggested that the human memory losses seen after hippocampal damage are due to retrieval failure. It would be of interest to know if the HL rat "forgets" faster than the normal rat in a task that we know it acquires with facility. With such data, we can begin to investigate the nature of this "forgetting" and formulate hypotheses concerning the role of the hippocampus in retrieval from long-term store.

\section{EXPERIMENT 1}

\footnotetext{
Method

Animals. Twenty-nine male Sprague-Dawley rats, obtained from a commercial breeder and weighing approximately $200 \mathrm{~g}$ at the beginning of the experiment, were used. They were housed in groups of five and six in transparent plastic breeding cages, were maintained on a 12-h-light/12-h-dark cycle, and were handled daily.

Surgery. Lesions of the dorsal hippocampus were made in the manner described by Winocur and Olds (1978). The animals were anesthetized with Nembutal $(40 \mathrm{mg} / \mathrm{kg})$ and positioned in a stereo-
} 
taxic instrument. The head was leveled by placing bregma and lambda in the same horizontal place. Lesions were produced by passing a 2-mA anodal dc current through an electrode made from a nichrome wire, $.25 \mathrm{~mm}$ in diameter and insulated except for $.5 \mathrm{~mm}$ at the tip. The electrode was placed stereotaxically, with four descents. The coordinates were $2.2 \mathrm{~mm}$ posterior to bregma, 1.5 and $2.5 \mathrm{~mm}$ to the right and left of the midline, and $3.0 \mathrm{~mm}$ below the dura. Cortical lesions were made in the same way, $1.2 \mathrm{~mm}$ ventral to the dura. Operated controls were fixed in the stereotaxic instrument, then heads were leveled, and holes were drilled in the skull, but no electrode was lowered.

At the completion of final retention testing, all animals were perfused with saline followed by $10 \%$ Formalin; the brains were removed and preserved in $10 \%$ Formalin. The brains were frozen and $50-\mu$ sections were made; every fourth section was saved and stained with cresyl violet.

Apparatus. A Thompson-Bryant box served as the conditioned avoidance apparatus; this has been described in detail elsewhere (Meyer \& Meyer, 1977). Briefly, it consisted of a startbox, connected to a choice area by a hinged door. The entire apparatus was painted orange, with the exception of the goalbox, which was black. The choice area measured $60 \times 30 \times 37 \mathrm{~cm}$; at the far end of the box were two hinged doors which were both orange during pretraining. There was a $10-\mathrm{cm}$ partition separating the two doors, fixed perpendicularly to the wall. During training, one of the doors was black and one was white. These doors gave access to the goalbox. The entire floor of the apparatus was an electrifiable grid through which a .5-mA intermittent shock could be passed. The apparatus was housed in a dark room and was illuminated by a $60-\mathrm{W}$ bulb.

Procedure. The animals were pretrained before surgery. They were carried to the experimental room in individual transparent plastic cages and spent the intertrial interval in these cages in the experimental room. Pretraining consisted of shaping the animal to leave the startbox, cross the electrified choice area, and push open the door giving access to the goalbox. The same pretraining protocol was followed for each rat; a removable partition was placed diagonally across the choice area so that there was access to only one door. The animal received 5 trials to each side. Then the partition was removed and replaced with the $10-\mathrm{cm}$ partition perpendicular to the back wall, between the two doors. The rat now received 16 trials with the orange doors, one of which was locked on each trial. This afforded the rat the opportunity to learn to correct a wrong choice by pushing on the other door. Twenty-four hours after pretraining, the rats were submitted to surgery. Ten days later they were trained to a $9 / 10$ criterion on the black/white discrimination in a single session. The orange doors were replaced with a black and a white door, the position of which was changed according to a modified Gellerman series. The white door was always locked. The intertrial interval was about $30 \mathrm{sec}$. The number of shocks per trial was recorded, as were errors of localization and the number of times per trial the rat touched the incorrect door.

During the training-to-test interval, the animals were maintained in the colony room, six per cage, under the usual 12-h-light/dark cycle. They were retested 21 days after training, to a $9 / 10$ criterion.

\section{Results}

Pretraining. Every rat used a spatial strategy in dealing with what was a virtually unsolvable problem (absence of visual discrimination) during the pretraining phase of the experiment. (Note that all rats were intact during pretraining.)

Discrimination. Cumulative acquisition curves can be seen in Figure 1. HLs required fewer trials to reach a $9 / 10$ criterion than did SLs $[\mathrm{t}(21)=3.57, \mathrm{p}<.01]$. There is no difference between CL and SL groups $[\mathrm{t}(17)=.02]$.

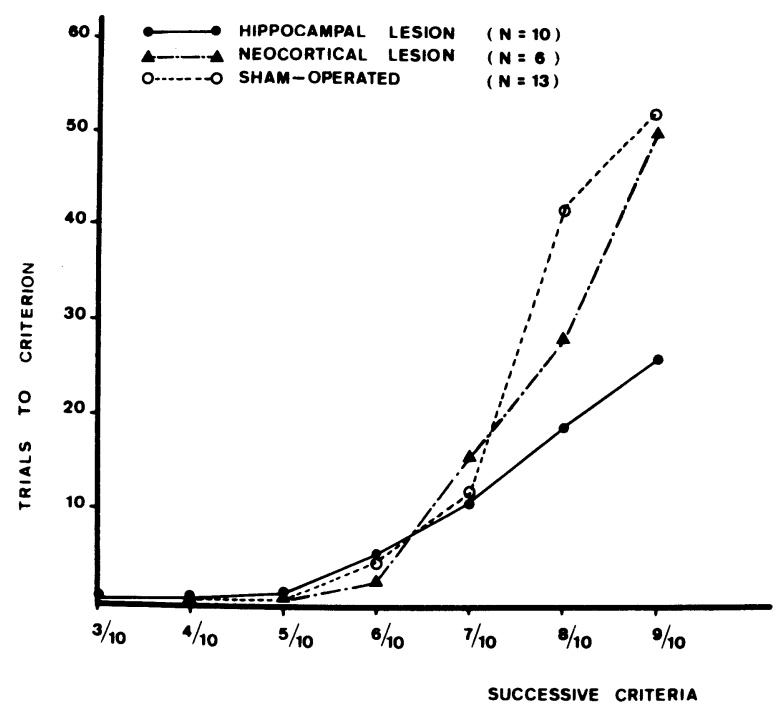

Figure 1. Mean number of trials to reach successive criteria. Hippocampal rats learn significantly faster than cortical and sham-operated rats.

Strategies. The individual behavioral strategies during acquisition are illustrated in Figure 2 (after Isaacson \& Kimble, 1972). White bars represent consecutive trials in which the rat behaves as if it were employing a spatial hypothesis, that is, choosing the door on the same side, regardless of the position of the visual stimulus. Table 1 is a resumé of the data concerning acquisition strategies. These data are expressed in terms of percentage of total trials because SLs and CLs have almost twice as many acquisition trials as do HLs. HLs have a significantly higher percentage of trials on which there is no discernible hypothesis behavior (interstrategy trials) $(\mathrm{t}=4.3, \mathrm{p}<.001)$. HLs have a lower percentage of trials with spatial strategies $(\mathrm{t}=5.57, \mathrm{p}<.001)$, and the duration of the spatial strategies is significantly shorter than that of the sham group $(\mathrm{t}=4.9, \mathrm{p}<.001)$. In other words, the HLs did not perseverate on the maladaptive directional solution to the problem, while the shams did. There were no significant differences between SLs and CLs on any of these measures.

Footshock. The mean number of shocks received by each group per trial can be seen in Figure 3. Both HLs and CLs received significantly more shocks during training than did SLs, especially during the early stages of acquisition $(t=4.07, p<.002$, and $t=2.02$, $\mathrm{p}<.05$, respectively).

Retention. The mean number of trials to reach $9 / 10$ criterion on reacquisition 3 weeks after training can be seen in Figure 4. There is very little forgetting in the control group, while both lesioned groups require a mean of 12 reacquisition trials. The difference between HL and SL groups is significant $(t=3.55$, $\mathrm{p}<.01)$. The difference between $\mathrm{CL}$ and SL groups 


\section{HYPOTHESIS BEHAVIOUR DURING ACQUISITION}

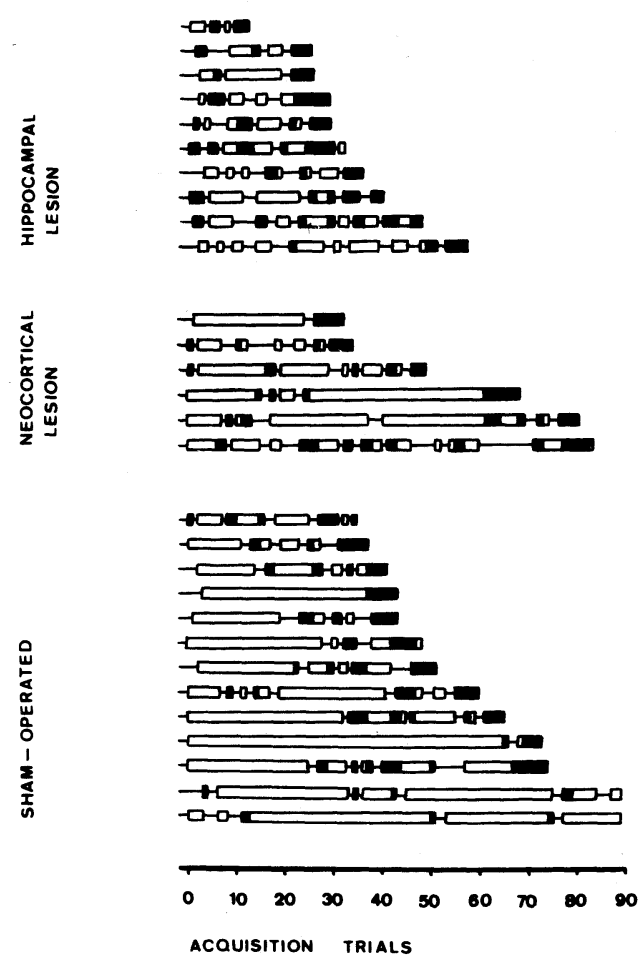

Figure 2. Open rectangles: number of trials during which rats exhibited a spatial strategy. Black rectangles: number of trials during which rats exhibited a visual strategy. Lines: number of trials during which rats exhibited no spatial or visual strategies.

only approached an acceptable level of significance, due to the larger variance and smaller $\mathbf{n}$ in the $\mathrm{CL}$ group $[t(17)=1.76, p<.10]$. It was noted that 9 of 10 SLs responded correctly on the first retention trial, which is significantly better than chance $(p=$ .02); 5 of 6 CLs responded correctly on the first trial $(\mathrm{p}=.10)$, but only 4 of $10 \mathrm{HLs}$ did so.

Histology. Representative hippocampal and cortical lesions can be seen in Figure 5. Hippocampal lesions were in the anterior dorsal portion of the hippocampus, sometimes extending into the commissure. There was no thalamic damage, and the fimbria was intact in all animals. All but one hippocampal animal sustained some damage to the overlying cortex and to the cingulum. Cortical lesions were about $1.5 \mathrm{~mm}$ in diameter and included, in most cases, damage to the cingulum.

\section{EXPERIMENT 2}

The pretraining procedure clearly enhanced lateral preference in the control animals; it is likely, then, that the pretraining had a negative as well as a positive effect on subsequent acquisition and that the lack of maladaptive place strategy in the HLs could account, at least in part, for their faster acquisition. Since surgery was performed after the pretraining and there was a 7-day interval between the pretraining and the training, we did not know if the lesion rendered the animals incapable of acting on place strategies or if this treatment induced "forgetting" of the pretraining experience, thereby nullifying its negative effect on acquisition.

The purpose of this experiment was to evaluate the effect of pretraining on behavioral strategy and on the number of trials to criterion during acquisition in hippocampal, cortical, and sham-operated animals. If the HLs had fewer place strategies than SLs because they had "forgotten" the pretraining (induced direction preference), then the elimination of pretraining might result in a decrease in the difference between the lesioned and nonlesioned groups. If, on the other hand, the lack of spatial hypothesis in the lesioned animals was due to a direct effect of the lesion on the animal's ability to organized spatial behavior, the acquisition differences should remain. The magnitude of the differences would depend upon the extent to which the SLs were impaired by the pretraining. Comparison of acquisition rates in Experiments 1 and 2 should answer this question.

\section{Method}

Animals. Rats with the same characteristics as those in Experiment 1 served as subjects in this experiment. They were housed and handled as in Experiment 1.

Surgery. The animals were operated on as in Experiment 1.

Apparatus. The discriminative avoidance chamber was the same as that used in Experiment 1.

Table 1

Strategies in Acquisition of Simultaneous Brightness Discrimination (Experiment 1)

\begin{tabular}{|c|c|c|c|c|c|c|c|c|}
\hline \multirow[b]{2}{*}{ Group } & \multicolumn{2}{|c|}{$\begin{array}{l}\text { Percentage of Trials } \\
\text { Without Strategy }\end{array}$} & \multicolumn{2}{|c|}{$\begin{array}{c}\text { Percentage of Trials } \\
\text { With Spatial Strategies }\end{array}$} & \multicolumn{2}{|c|}{$\begin{array}{c}\text { Longest Spatial } \\
\text { Strategy }\end{array}$} & \multicolumn{2}{|c|}{$\begin{array}{l}\text { Percentage of Trials } \\
\text { With Visual Strategies }\end{array}$} \\
\hline & Mean & SD & Mean & SD & Mean & SD & Mean & SD \\
\hline Sham & 16.8 & 2.13 & 66.18 & 3.79 & 26.2 & 4.13 & 8.8 & 1.53 \\
\hline $\mathrm{HL}$ & $33.0^{*}$ & 3.15 & $39.75^{*}$ & 2.98 & $5.7^{*}$ & .89 & $15.3^{*}$ & 3.06 \\
\hline CL & 23.1 & 6.44 & 57.51 & 8.04 & 17.5 & 4.80 & 8.8 & 2.82 \\
\hline
\end{tabular}

Note-Significance levels are results of $t$ tests between $H L$ and $S L$ and between $C L$ and $S L . \quad \quad{ }^{*} p<.001$. 


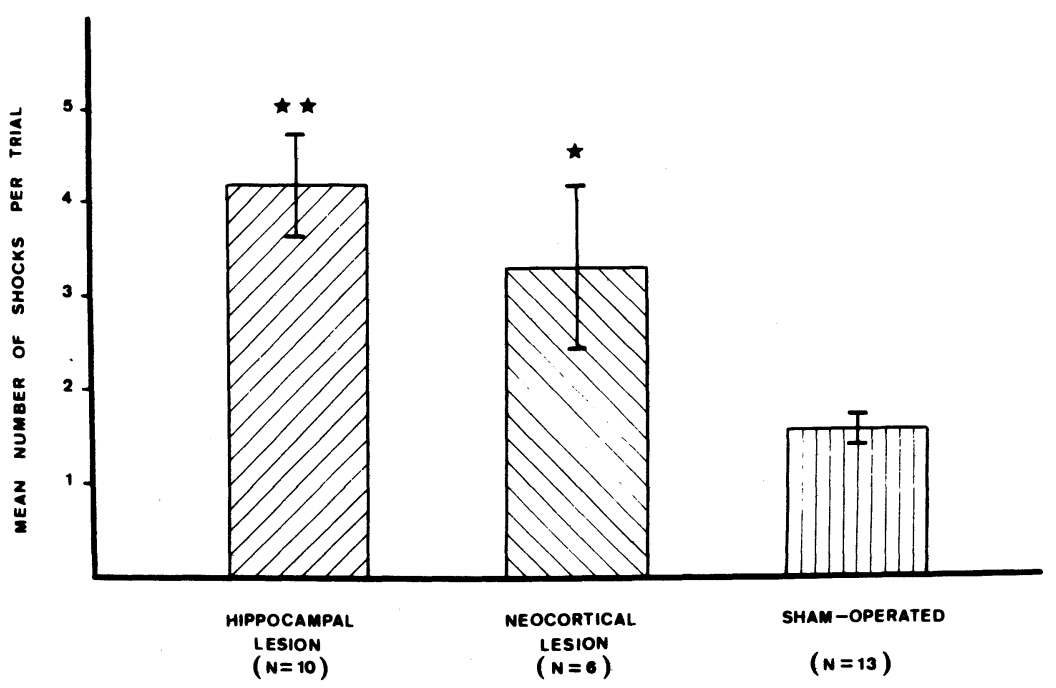

Figure 3. Mean shocks per trial: Sham-operated rats received significantly fewer shocks than either the cortical or the hippocampal group. ${ }^{*} p<.05 ;{ }^{* *} p<.01$.

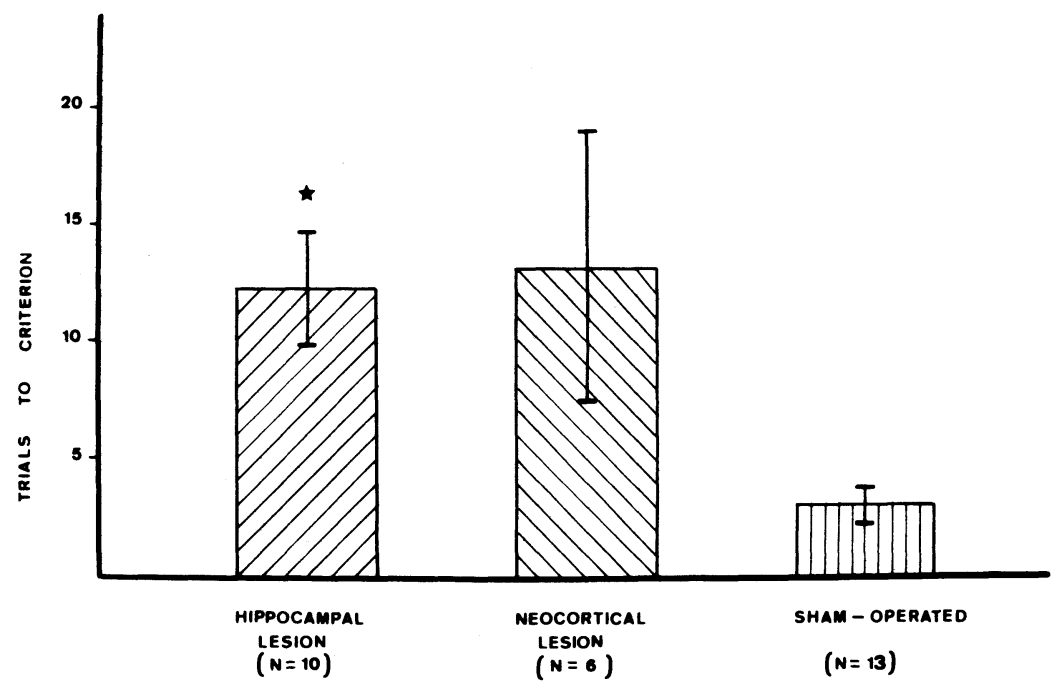

Figure 4. Long-term retention of simultaneous brightness discrimination learning in rats after hippocampal lesions. Training-to-test interval was 3 weeks. The shamoperated animals had significantly better retention than hippocampal or cortical animals.

Procedure. The rats were trained in a single session. Each rat was placed in the start compartment, the door was opened by the experimenter, and the shock was delivered $3 \mathrm{sec}$ later. For the first two or three trials, the unlocked door was opened by the experimenter as soon as the animal was in front of it. For the next few trials, the door was opened partially. During this shaping period, the position of the correct discrimination was determined by the Gellerman series. As soon as the rat pushed the door unassisted, the experimenter no longer intervened and the training proceeded as in Experiment 1 until the animal reached the criterion of $9 / 10$.

\section{Results and Discussion}

The elimination of the pretraining phase did not have a large effect on the number of trials to criterion in any group (see Figure 6). The difference between
HL and SL was significant, thus replicating the acquisition results of Experiment $1[\mathrm{t}(15)=3.4, \mathrm{p}<.01]$. The difference between SL and CL was not significant. The elimination of the pretraining phase did have an effect on the incidence of place strategies in sham-lesioned rats. As might have been expected, this group displayed fewer spatial hypotheses early in acquisition (compare Figure 2 with Figure 7.) Nevertheless, this group still have a significantly higher percentage of spatial strategies than did the HL group $(t=2.74, p<.05)$, and these spatial strategies were of a significantly longer duration $(t=3.24, \mathrm{p}<.01$; see Table 2).

As in Experiment 1, both the HLs and the CLs 


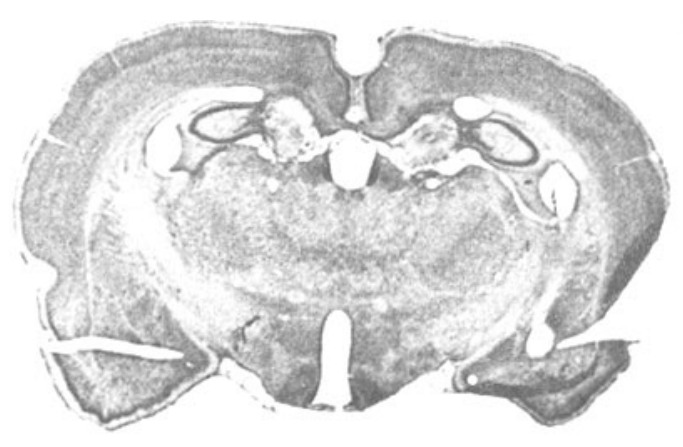

responded correctly on the first retention trial $(p=$ $.015)$, although their subsequent performance was as poor as that of the HL group. This replicates the nonsignificant first-trial tendency for this group in Experiment 1.

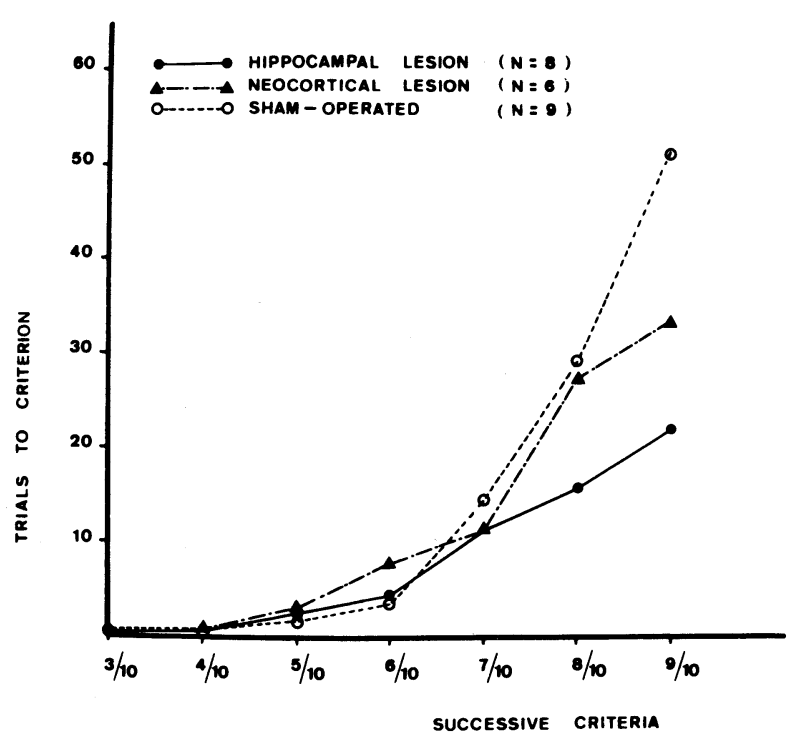

Figure 6. Mean number of trials to reach successive criteria. Hippocampal rats learned significantly faster than cortical and sham-operated rats.

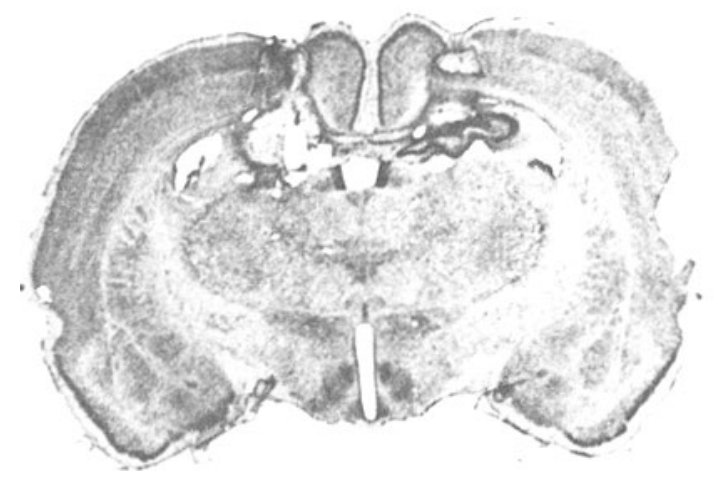

Figure 5. Photographs of representative cross sections of hippocampal, cortical, and combined cortical-hippocampal lesions.

received more shocks per trial than did the SLs $(\mathrm{t}=$ $3.39, \mathrm{p}<.01$, and $\mathrm{t}=1.75, \mathrm{p}<.10$, respectively; see Figure 8).

Retention. HLs and CLs required significantly more trials to reattain the $9 / 10$ criterion than did SLs after the 3-week training-to-test interval $(t=2.75, \mathrm{p}<.05$; $t=3.13, p<.01$, respectively; see Figure 9). Further evidence for the memory deficit in HLs was that only 4 of 8 made the correct choice on the first test trial, while 7 of 8 SLs responded correctly on the first trial, a performance significantly better than chance $(p=.035)$. A curious finding was that 6 of the 6 CLs

\section{HYPOTHESIS BEHAVIOUR DURING ACQUISITION}

[ WITHOUT PRETRAINING]
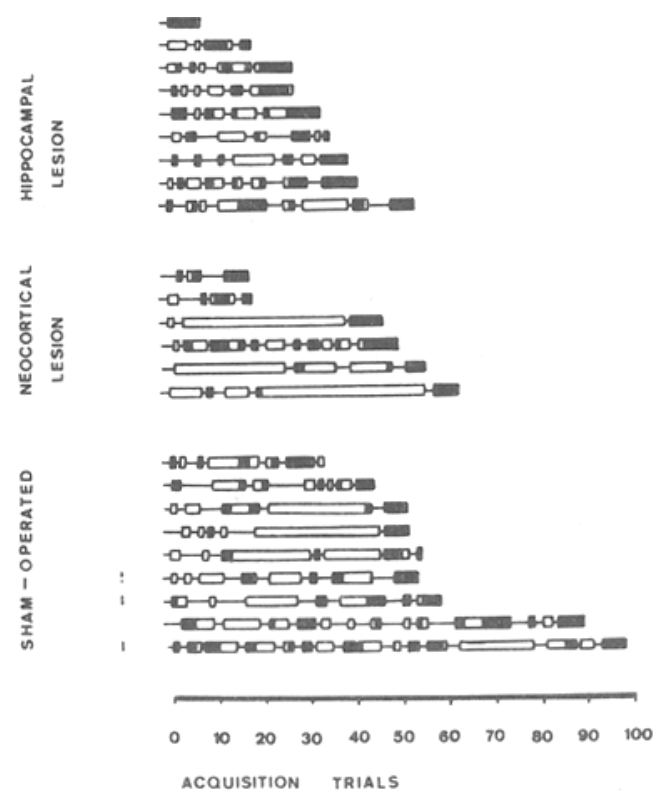

Figure 7. Open rectangles: number of trials during which rats exhibited a spatial strategy. Black rectangles: number of trials during which rats exhibited a visual strategy. Lines: number of trials during which rats exhibited no spatial or visual strategies. 
Table 2

Strategies in Acquisition of Simultaneous Brightness Discrimination Without a Pretraining Session (Experiment 2)

\begin{tabular}{|c|c|c|c|c|c|c|c|c|}
\hline \multirow[b]{2}{*}{ Group } & \multicolumn{2}{|c|}{$\begin{array}{l}\text { Percentage of Inter- } \\
\text { strategy Trials } \\
\end{array}$} & \multicolumn{2}{|c|}{$\begin{array}{c}\text { Percentage of Trials With } \\
\text { Spatial Strategy }\end{array}$} & \multicolumn{2}{|c|}{$\begin{array}{c}\text { Longest Spatial } \\
\text { Strategy }\end{array}$} & \multicolumn{2}{|c|}{$\begin{array}{c}\text { Percentage of Trials With } \\
\text { Visual Strategies }\end{array}$} \\
\hline & Mean & SD & Mean & SD & Mean & SD & Mean & SD \\
\hline Sham & 34.7 & 3.06 & 47.87 & 4.39 & 13.3 & 2.45 & 13.9 & 2.52 \\
\hline $\mathrm{HL}$ & 30.4 & 4.41 & $26.95^{*}$ & 3.51 & $4.7^{*}$ & 1.05 & 18.5 & 3.48 \\
\hline $\mathrm{CL}$ & 26.3 & 6.90 & 49.45 & 13.90 & 17.3 & 6.49 & 13.4 & 5.79 \\
\hline
\end{tabular}

Note-Significance levels are results of t tests between $H L$ and $S L$ and between $C L$ and $S L . \quad \quad{ }^{*} p<.01$.

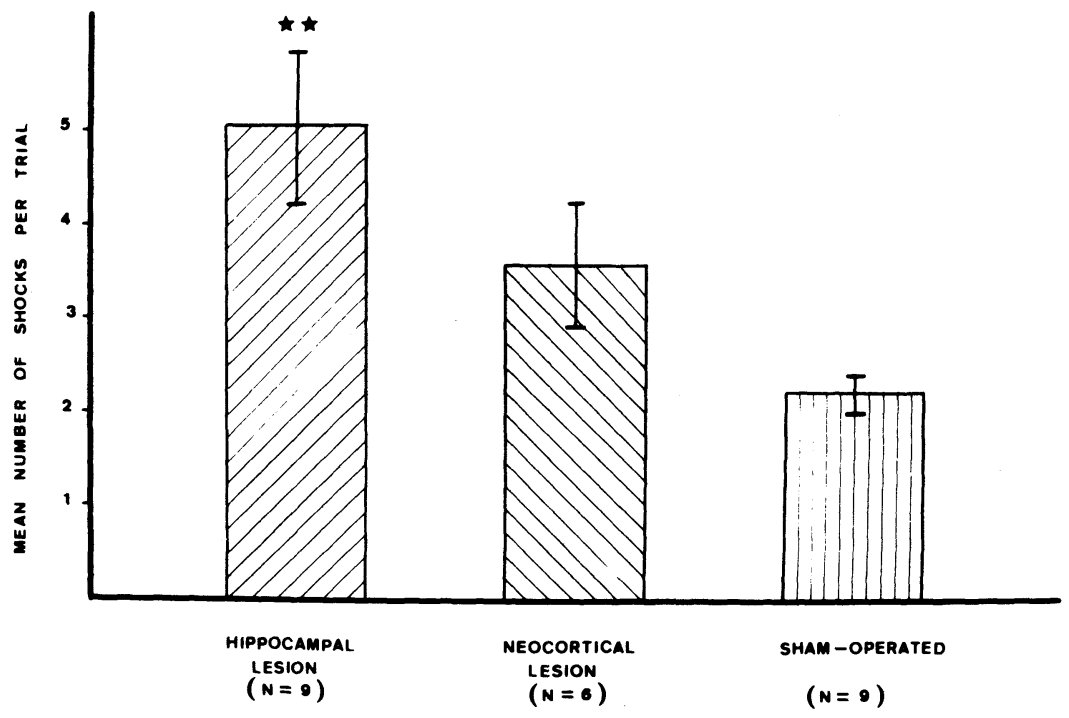

Figure 8. Mean shocks per trial: Sham-operated rats received significantly fewer shocks than either the cortical or hippocampal group. ${ }^{\star} \mathrm{p}<.05 ;{ }^{* *} \mathrm{p}<.01$.

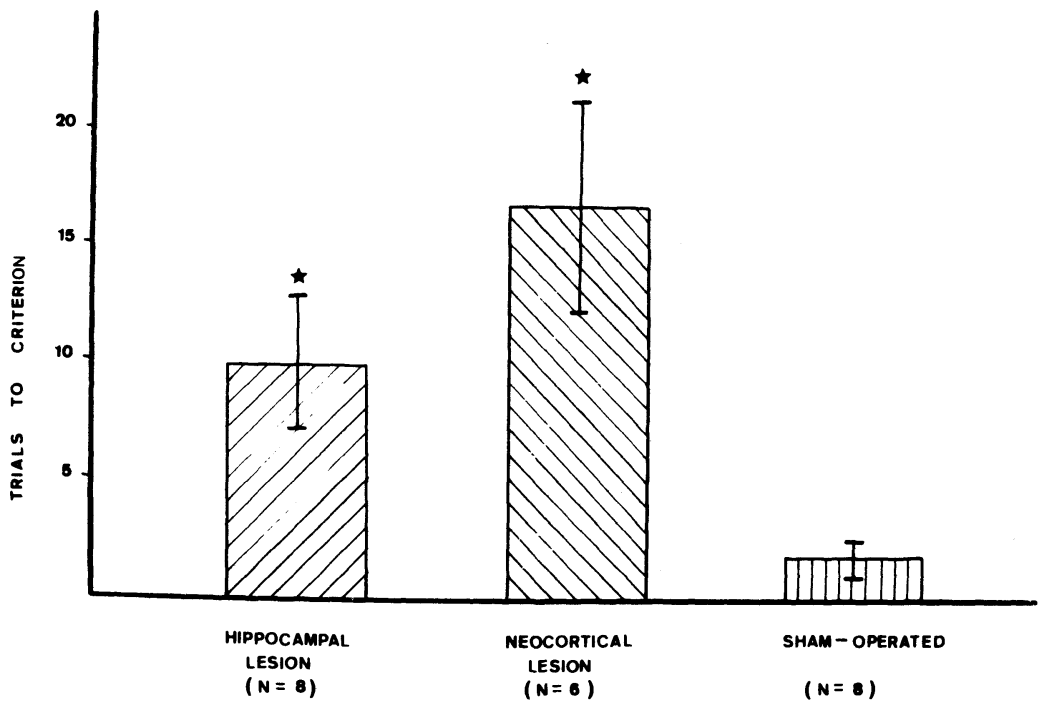

Figure 9. Long-term retention of simultaneous brightness discrimination learning in rats after hippocampal lesions. Training-to-test interval was 3 weeks. The shamoperated animals had significantly better retention than hippocampal or cortical animals. 


\section{EXPERIMENT 3}

The purpose of this experiment was to evaluate retention performance $24 \mathrm{~h}$ after training, in order to determine if the memory deficits seen in Experiments 1 and 2 were dependent upon the extended trainingto-test interval. The experiment was also to serve as a replication of the acquisition effects observed in the first two experiments.

\section{Method}

Twelve rats with the same characteristics as those in the previous experiments were used. Six received hippocampal lesions and six were sham-operated, as described in the previous experiments. They were trained after recovery from the surgery, using the same procedure as in Experiment 2. They were tested $24 \mathrm{~h}$ after training.

\section{Results}

Acquisition strategies and trials to criterion were similar to those seen in the two previous experiments. SLs required a mean of 72 trials to criterion and HLs required $37[\mathrm{t}(10)=3.19, \mathrm{p}$.01]. HLs had a lower percentage of spatial strategies $(t=2.01, p=.10)$, and these were of a significantly shorter mean duration than those of the SL group $(t=3.27, p<.01)$.

When retrained to the $9 / 10$ criterion, there was no evidence of a memory deficit in the HL group. These animals required a median of 0 trials and the SLs required 3.5 (n.s.). The lack of difference could be due to a ceiling effect, since so many rats showed $100 \%$ savings. Perhaps partially trained HLs would show a retention deficit at short training-to-test intervals. Under the present conditions, however, the long interval was necessary to show a memory deficit in the lesioned animals.

\section{GENERAL DISCUSSION}

The principle findings of these experiments can be summarized as follows: (1) Rats lesioned in the dorsal hippocampus learn a discrimination avoidance task in fewer trials than do cortically lesioned or shamoperated controls. (2) Analysis of hypotheses behavior during acquisition reveals that HLs have significantly fewer spatial strategies than normals and that they change strategies more frequently, that is, perseverate less, than normal or cortically lesioned animals. Although this difference is greater when perseveration on a spatial hypothesis is enhanced by a pretraining session, it remains, nevertheless, when spatial perseveration is less pronounced in control animals. (3) When animals are tested after a 3-week trainingto-test interval, normal animals have very good retention, while both $\mathrm{HL}$ and $\mathrm{CL}$ rats have poor retention. (4) This poor retention is not seen $24 \mathrm{~h}$ after training.

\section{Hypothesis Behavior and Rate of Acquisition}

The present finding that HL animals learn a simul- taneous discrimination task faster than normal or cortically lesioned animals does not agree with the prevailing literature, although the effect of the lesion on this type of learning has not been as widely studied as has its effect on other behaviors. For the most part, the few existing studies have found no effect of this lesion on simultaneous discrimination learning (Kimble \& Kimble, 1970; Winocur \& Olds, 1978) with positive reinforcement.

Isaacson and Kimble (1972), in reanalyzing the results of an earlier study, report that HL animals tended to learn a simultaneous brightness discrimination faster than control animals, although the differences did not reach statistical significance because of the large within-group variability. The conditions of that experiment differed from those of the present experiments: the discrimination training took place in a Y-maze, the response was positively reinforced, the trials were spaced over several days, and a noncorrection procedure was used. The analysis of "hypothesis behavior" reveals specific patterns of behavior: While normal animals displayed many short series of visual or place hypotheses, HL animals showed fewer hypotheses and perseverated on spatial, but not visual, strategies. HL rats had fewer interstrategy trials (trials on which no strategy could be discerned) than normal or CL rats. These results led Isaacson \& Kimble (1972) to conclude that the "inflexibility of the animals with hippocampal lesions stems from their extended series of responses in accord with a place hypothesis. These animals seem extremely reluctant to give up the spatial hypothesis in the face of inconsistent reinforcement for this behavior"' (p. 784).

The results of the three experiments reported here clearly lead to the opposite conclusion. HLs learn a visual discrimination problem significantly and reliably faster than do SL or CL controls, and they do not perseverate on any strategy. In fact, in Experiment 1 , in which the pretraining clearly established a presolution spatial strategy, as could be seen from the very beginning of acquisition in control animals, HLs gave no indication in the early stages of acquisition of an influence of this presurgically acquired behavior (see Figure 8).

The study that is most striking in its discrepancy with the present results is that of Duncan and Duncan (1971), in which septal and hippocampal rats were found to be severely impaired in acquisition of a simultaneous discriminative avoidance task and to perseverate on a spatial hypothesis. The lesions in that experiment were slightly posterior and more lateral than ours, but similar in size. In the Duncans' experiment, the rats had been subjected to extensive free operant avoidance training prior to the visual discrimination task. Furthermore, the interval between surgery and the T-maze training was at least 35 days, while in the present experiments it was 7-10 days. It is possible that the operant avoidance training 
and/or the time between surgery and training could result in functional changes in the systems implicated in discrimination learning. Whether this can account for the differences in results cannot be determined without further experiments.

The layout of our apparatus was quite different from that of visual discrimination studies that report perseveration on a spatial hypothesis in HLs, and this difference could account for the differences in acquisition strategies. Indeed, in a study by Dabrowska and Drzewiecka (1975), using the same Thompson-Bryant apparatus as the present experiments, with food reinforcement, rats with medical septal lesions "changed their directional responses more often with shorter bursts of responses than normals"' (p. 260). Furthermore, these authors add that normal rats made more directional responses very early in acquisition, while septals exhibited this behavior later. These results are strikingly similar to our observations of HLs (see Figure 2). It is important to emphasize that Dabrowska and Drzewiecka (1975) used the same apparatus as we did, but with food reinforcement. Thus, incidence and perseveration on spatial strategies in hippocampal and septal rats appear to be independent of the nature of the reinforcement, but a function of the geometric layout of the training field. Spatial strategies can be based either on contextual cues requiring the use of a locale or cognitive mapping system or on responseproduced, ballistic cues that are independent of the animal's perception of place and context. Which cues the intact rat uses in formulating the spatial strategies will depend to a large extent on the position of the discriminanda and the nature of the response required (see Restle, 1957). A maze layout in which the rat does not see the goal and discriminanda until the choice point, and then is required to turn toward the goal, would favor the use of ballistic cues. In the Thompson apparatus, the proximity of the discriminanda to one another and the relatively long distance from the startbox to the doors of the goalbox results in an angle of $21 \mathrm{deg}$ being formed by lines from the center of the startbox to the center of the goal doors. This, taken with the correction procedure used and the unstructured choice area, would minimize the role of responseproduced ballistic cues in guiding the spatial hypothesis. The spatial behavior of SL and CLs would then have to be guided by place cues. It is tempting to take the present results as further evidence that the hippocampus is intimately involved in elaboration of space or "cognitive mapping," since HLs do not have this spatial strategy based on place cues (O'Keefe \& Nadel, 1979).

It has been suggested that hippocampal lesions favor an immediate mobilization of "taxon systems"- to use O'Keefe and Nadel's terminology-that is, formation of hypotheses based on visual cues. Since the "locale systems" are not available to them, according to this theory of hippocampal function. The perseveration in maze situations might be explained by the fact that hippocampal animals do not process the information concerning the alternative place and that it is only when they start focusing on the visual cues that they remember from one trial to the next that there is a binary choice. As suggested by Olton, the reliance on exclusively ballistic cues early in the learning session results in perseveration (Olton \& Werz, 1978). In our experimental setup, which does not promote the use of response-produced cues, the HL rats learn faster, because they do not have the initial place cues upon which to fixate and because, for these animals, the most salient cues in the Thompson apparatus are the visual ones.

\section{Shock Escape and Avoidance}

Lesioned animals, both hippocampal and cortical, consistently received significantly more shock than normals, especially early in the training session. This difference in ability to escape efficiently cannot account for differences in rate of learning, since there was no correlation between amount of shock received and trials to criterion. Moreover, cortical rats, while receiving the same amount of shock as hippocampals, learned at the same rate as normals. During retention testing, this difference in amount of shock received at each trial persisted. Black et al. (1977) have noted that in other escape-avoidance situations, hippocampal rats have difficulty in escaping to a place in the absence of salient cues marking that place. In the early stages of escape learning in our experimental setup, the animals had to acquire a memory for the spatial relation between shock and goal and learn that the shock is escaped not just by running, but by running to a place (the goalbox). On later trials, when the rat starts attending to the visual stimuli, the hippocampals are facilitated in the escape response, because the safe place is marked by a black or white door.

\section{Long-Term Retention}

Hippocampal. The retention deficits in HL rats were seen in the number of trials needed to attain $9 / 10$ criterion, as well as in the first response choice. It could be argued that HL rats forgot faster simply because they learned faster, that is, had fewer acquisition trials. This is an untenable explanation for two reasons. There was no correlation between rate of acquisition and retention score within any of the groups. Moreover, cortical rats had approximately the same number of acquisition trials as sham-operated animals, yet had a poor retention performance, similar to that of the HL group.

It has been reported that HLs are more disturbed than normals by changes in the experimental procedure from training to testing. And, indeed, when the animals are tested $24 \mathrm{~h}$ after training under the same conditions, 
there are no differences in performance (Experiment 3); it is the long training-to-test interval, and not changes in the experimental conditions, which produces the retention deficit. Jarrard (1975) has shown that HLs are more sensitive to interference than are normals; they have poor retention when there is interpolated activity between training and testing. The amount of potential interference in the form of sensorymotor experience and social interaction will, of course, increase with the length of the training-to-test interval.

If $\mathrm{HL}$ rats do not use information concerning place, as our acquisition results suggest, then we might expect that there would be a deficiency in coding within a spatiotemporal context and a subsequent deficit in long-term retention due to retrieval failure (see O'Keefe \& Nadel, 1979). The importance of background stimuli or context has been emphasized in memory work with animals, using classical conditioning paradigms (Asratyan, 1961; Kupalov, 1961; Wagner, 1976), in human verbal learning (Tulving, 1974), and in clinical studies of amnesics (Butters \& Cermack, 1975; Kinsbourne \& Wood, 1975; Weiskrantz, 1977). Recent maze studies in our laboratory have shown that rats that are exposed to contextual stimuli found in the experimental room immediately prior to the retention test after a 3-week training-to-test interval make fewer errors than rats placed directly in the maze. Presumably, the memory for this task was elaborated within the spatiotemporal context of the experimental room, and these background stimuli acted as retrieval cues to facilitate the organization of information concerning response contingencies. Based on these data, we suggested that memory retrieval processes depend not only on the information stored, but also on the perceptual and information-processing activities occurring immediately prior to the retention test (Deweer, Sara, \& Hars, 1980). The present results provide indirect support for this position. If we accept that HLs are deficient in cognitive mapping ability (as the acquisition strategy results strongly suggest), we would predict that they would be deficient in longterm memory, because contextual cues were not processed along with the information concerning visual cues and response contingencies. Thus, those animals require more time and more specific information in order to retrieve the information and organize an adaptive response. This can be seen in the fact that HL rats make more errors in the beginning of the session, but still have considerable savings over original acquisition scores.

Support for this view comes from an observation made in an experiment of Jackson and Strong (1969). They report that HLs learn a barpress alternation task faster than do controls. What is interesting in examining these results is that lesioned animals showed a severe warm-up decrement during the first $3 \mathrm{~min}$ of every test session. The control rats, while not being able to attain the same level of performance as the HLs, nevertheless, did not exhibit this warm-up decrement. We would suggest that the warm-up decrement is a retrieval deficit (see Spear, Gordon, \& Martin, 1973) due to the failure of the HLs to elaborate the memory for the task within the context of the experimental surroundings. Retrieval processes are, then, not triggered by the background stimuli, but only by the presentation of the conditioned stimuli and the reinforcement; thus more time is required in the initial session for the HL rat to organize the appropriate behavior.

Cortical. CL animals learned the visual discrimination at the same rate and using the same strategies as normal rats. The only thing that distinguished these animals from sham-operated controls during acquisition is the fact that the CLs, like the HLs, received significantly more shock than normals. This amount of shock received during acquisition correlated neither with rate of acquisition nor with retention level. The poor retention seen by the CLs after the 3-week training-to-test interval is seen by the number of trials required to relearn to a $9 / 10$ correct responses criterion. However, if only the first trial or only the first two trials of the retention test are considered, CL animals, as well as sham-operated rats, perform significantly better than chance, while the HLs have chance performance (which we are calling a warm-up decrement).

Performance on the first trial is probably the most accurate measure of memory retrieval, uncontaminated by relearning processes. It is difficult to regard the present results of retention performance deficit in terms of memory loss, but we have no hypothesis to explain why the CLs should show good retention, in having the first choices correct, and then are unable to maintain the behavior over the next few trials; the deterioration of the behavior occurs early in the session, as can be seen by the fact that, even though the first two responses were almost always correct, this group made significantly more errors in the first 10 trials than did the control group. The results cannot be easily explained in terms of a tendency to lateral perseveration, since the first two trials were lateral alternations.

Meyer and Meyer (1977) report retention deficits in rats with cortical lesions on the same task that we use in our experiments. Their animals were trained before the lesion, and the results replicated the findings of Lashley, that such lesions do not affect the rat's capacity to learn a visual discrimination task, but do produce profound retrograde memory deficits. The Meyers' lesions, as well as Lashley's, involved the entire posterior cortex, while ours were small lesions of the dorsomedial cortex just posterior to the bregma. It is not possible to tell from the Meyers' data if lesioned rats respond correctly on the first trials, since they report only relearning data.

The nature of the memory deficits resulting from 
each of the two lesions remains to be investigated. Most of the HLs had concomitant cortical and cingulate damage, and, consequently, we do not know if the cortical lesion is not only a sufficient condition, but also a necessary condition for the long-term memory deficit. The fact that the two lesions had different effects on acquisition behavior suggests that they could be affecting memory in different ways. Recall that, in acquisition, both HLs and CLs received significantly more shocks than controls, but the CLs required as many acquisition trials as controls and exhibited strategy behavior markedly different from that of HLs and undistinguishable from that of controls. This suggests that the hippocampal lesion itself was responsible for the behavioral differences in acquisition (i.e., lack of spatial strategies). The retention deficits could be due to the cingulum damage present in most of the animals in both the CL and HL groups.

The cingulum bundle represents a major neocortical afferent supply to the hippocampal formation. Sectioning this fiber system results in degeneration of the entorhinal area, presubiculum, and parasubiculum of the hippocampal formation (White, 1959). The cingulum has been shown to supply about $50 \%$ of serotonin neurons in the dorsal hippocampus and $20 \%$ of serotonin neurons in the ventral hippocampus (Storm-Mathisen \& Guldenberg, 1974). There is recent evidence that some noradrenergic neurons of the hippocampus are also supplied by projections through this fiber system (Azmitia, Note 1). This neuroanatomical and neurochemical evidence clearly suggests that damage to the cingulum bundle will have an important impact on hippocampal function and especially on neocortical-limbic system integration. It is this integrative activity which might be essential for efficient memory organization after a long training-totest interval.

There was one difference in the results of the retention test between HLs and CLs which is rather puzzling. CLs made correct choices on the first retention trial, but their subsequent performance in terms of trials to criterion was no better than that of the HLs. The fact that the CLs did not have the same retrieval deficit concerning the visual discrimination at the beginning of the test, as the HLs clearly showed, suggests that the deficits might not be qualitatively equal. Studies are presently under way to determine under what conditions these memory deficits can be alleviated. It would be of interest to know if the cortical and hippocampal preparations respond differently to different facilitation procedures, such as manipulation of retrieval cues at retention testing, to reactivation during the training-totest interval, or to pharmacological manipulations.

We have recently developed a technique by which we can make a small lesion in the dorsal hippocampus without damaging the overlying cortex and cingulum.
The use of this technique, along with the technique of cutting the cingulum fibers, should elucidate the relative role of these structures in memory retrieval and organization after a long training-to-test interval.

\section{REFERENCE NOTE}

1. Azmitia, E. Personal communication, 1980.

\section{REFERENCES}

Altman, R., Brunner, R., \& Bayer, S. The hippocampus and behavioral maturation. Behavioral Biology, 1973, 8, 557-596.

Asratyan, E. A. The initiation and localization of cortical inhibition in the conditioned reflex arc. In N. Kline (Ed.), Pavlovian Conference on Higher Nervous Activity. Annals of the New York Academy of Sciences, 1961, 92, 813-1198.

Вцаск, А. Hippocampal electrical activity and behavior. In R. Isaacson \& K. Pribram (Eds.), The hippocampus (Vol. 2). New York: Plenum Press, 1975.

Black, A., NADEL, L., \& O'KeEfE, J. Hippocampal function in avoidance learning and punishment. Psychological Bulletin, 1977, 84, 1107-1129.

Butters, N., \& Cermack, L. Some analysis of amnesia syndromes in brain damaged patients. In R. Isaacson \& K. Pribram (Eds.), The hippocampus (Vol. 2). New York: Plenum Press, 1975.

Dabrowska, J., \& Drzewiecka, B. Comparison of the septal lesion effects on visual and spatial discriminations in rats. Acta Neurobiologica Experimentalis, 1975, 35, 255-271.

Deweer, B., Sara, S. J., \& Hars, B. Contextual cues and memory retrieval in rats: Alleviation of forgetting by a pretest exposure to background stimuli. Animal Learning \& Behavior, 1980, 8, 265-272.

Douglas, R. J. The development of hippocampal function: Implications for theory and therapy. In R. Isaacson \& K. Pribram (Eds.), The hippocampus (Vol. 2). New York: Plenum Press, 1975.

Duncan, P., \& Duncan, N. Free operant and T-maze avoidance performance by septal and hippocampal-damaged rats. Physiology \& Behavior, 1971, 7, 687-693.

GAFFAN, D. Loss of recognition memory in rats with lesions of the fornix. Neuropsychology, 1972, 10, 327-341.

Gray, J., Rawlins, J., \& Feldon, J. Brain mechanisms in the inhibition of behavior. In A. Dickinson \& R. Boakes (Eds.), Mechanisms of learning and motivation: A memorial volume for Jerzy Konorski. Hillsdale, N.J: Erlbaum, 1977.

Green, R., Beatty, W., \& Schwartzbaum, J. Comparative effects of septo-hippocampal and caudate lesions on avoidance behavior in rats. Journal of Comparative and Physiological Psychology, 1967, 64, 444-452.

Grossman, S. P. An experiment dissection of the septal syndrome. In J. Gray (Ed.), Function of the septo-hippocampal system. Amsterdam: Elsevier, 1978 .

IsAacson, R. L. Hippocampal destruction in man and other animals. Neuropsychologia, 1972, 10, 47-64.

IsaAcson, R. L., \& Kimble, D. Lesions of the limbic system: Their effects upon hypotheses and frustration. Behavioral Biology, 1972, 7, 767-793.

Jackson, W., \& Strong, P. Differential effects of hippocampal lesions upon sequential tasks and maze learning by the rat. Journal of Comparative and Physiological Psychology, 1969, 68, 442-450.

JARRARD, L. E. Role of interference in retention by rats with hippocampa! lesions. Journal of Comparative and Physiological Psychologv, 1975, 89, 400-408. 
Kimble, D. Hippocampus and interval inhibition. Psychological Bulletin, 1968, 70, 285-295.

Kimble, D., \& Kimble, R. The effect of hippocampal lesions on extinction and "hypothesis" behavior in rats. Physiology \& Behavior, 1970, 5, 735-738.

Kinsbourne, M., \& Wood, F. Short-term memory and the amnesia syndrome. In D. Deutsch \& J. A. Deutsch (Eds.), Short-term memory. New York: Academic Press, 1975.

Kupalov, P. S. Some normal and pathological processes in the brain. In N. Kline (Ed.), Pavlovian Conference on Higher Nervous Activity. Annals of the New York Academy of Sciences, 1961, 92, 813-1198.

MaнUT, H. A selective spatial deficit after transection of the fornix. Neuropsychologia, 1972, 10, 409-424.

Meyer, D. R., \& Meyer, P. M. Dynamics and bases of recoveries of functions after injuries to the cerebral cortex. Physiological Psychology, 1977, 5, 133-165.

O'KeEFe, J., \& Black, A. Single unit lesion experiments on the sensory input to the hippocampus cognitive map. In J. Gray (Ed.), Functions of the septo-hippocampal system. Amsterdam: Elsevier, 1978.

O'Keefe, J., \& Conway, D. Hippocampal place units in the freely moving rat: Why they fire where they fire. Experimental Brain Research, 1978, 31, 573-590.

O'KeEfe, J., \& NAdEL, L. Review of The hippocampus as a cognitive map. Neuroscience, 1979, 4, 863-864.

O'Keefe, J., Nadel, L., Keighty, S., \& Kill, D. Fornix lesions selectively abolish place learning in the rat. Experimental Neurology, 1975, 48, 152-166.

Olton, D., \& Samuelson, R. Remembrance of places passed: Spatial memory in rats. Journal of Experimental Psychology: Animal Behavior Processes, 1976, 2, 97-116.

Olton, D., \& Werz, M. A. Hippocampal function and behavior: Spatial discrimination and response inhibition. Physiology \& Behavior, 1978, 20, 597-605.

Osborne, B., \& Black, A. A detailed analysis of behavior during the transition from acquisition to extinction in rats with fornix lesions. Behavioral Biology, 1978, 23, 271-290.

Restle, F. Discrimination of cues in mazes: A resolution of places-vs-response question. Psychological Review, 1957, 64, 217-228.

Sara, S. J., Deweer, B., \& Hars, B. Forgetting as a lapse, not a loss: Facilitation of retrieval by a reminder. Bulletin d'Information de la Société Belge de Psychologie, 1976, 1, 22-25.
Sara, S. J., Deweer, B., \& Hars, B. Reticular stimulation facilitates retrieval of a 'forgotten' maze habit. Neuroscience Letters, 1980, 18, 211-217.

Solomon, P. Role of the hippocampus in blocking and conditioned inhibition of the rabbit's nictitating membrane response. Journal of Comparative and Physiological Psychology, 1977, 91, 407-417.

Solomon, P. Temporal versus spatial information processing theories of hippocampal function. Psychological Bulletin, $1979,86,1271-1279$.

Spear, N., Gordon; W., \& Martin, P. Warm-up decrement as failure in memory retrieval in the rat. Journal of Comparative and Physiological Psychology, 1973, 85, 601-614.

Storm-Mathisen, J., \& Guldenberg, H. C. 5-Hydroxytryptamine and noradrenaline in the hippocampal region: Effect of transection of afferent pathways on endogenous levels, high affinity uptake and some transmitter related enzymes. Journal of Neurochemistry, 1974, 22, 793-803.

Tulving, E. Cue dependent forgetting. American Scientist, 1974, 62, 74-82.

WAGNe R, A. Priming in STM: An information processing mechanism for self-generated or retrieval-generated depression in performance. In T. J. Tighe \& R. N. Leaton (Eds.), Habituation: Perspectives from child development, animal behavior and neurophysiology. Hillsdale, N.J: Erlbaum, 1976.

Weiskrantz, L. Trying to bridge some neuropsychological gaps between monkey and man. British Journal of Psychology, 1977, 68, 431-445.

Weiskrantz, L., \& Warrington, E. The problem of the amnexis syndrome in man and animals. In K. H. Pribram \& R. L. Isaacson (Eds.), The hippocampus (Vol. 2). New York: Plenum Press, 1975.

White, L. E. Ipsilateral afferents to the hippocampal formation in the albino rat. Journal of Comparative Neurology, 1959, $113,1$.

Winocur, G., \& Bindra, D. Effects of additional cues on passive avoidance learning and extinction in rats with hippocampal lesions. Physiology \& Behavior, 1976, 17, 915-920.

Winocur, G., \& OLDS, J. Effects of context manipulation on memory and reversal learning in rats with hippocampal lesions. Journal of Comparative and Physiological Psychology, 1978, 92, 312-321

(Received for publication March 19, 1980; revision accepted October 7,1980 .) 